\title{
BIENAL DE SÃO PAULO impacto na cultura brasileira
}

\author{
Rita Alves Oliveira \\ Socióloga, Professora da Faculdade de Design de Multimídia do Senac-SP
}

\begin{abstract}
Resumo: O principal evento de artes plásticas no Brasil é a Bienal de São Paulo. Na metade do século XX, um novo cenário cultural possibilitou a criação do Museu de Arte Moderna de São Paulo e da Bienal, que chegou ao final do século como um dos mais importantes eventos do circuito mundial, detentora de pesados investimentos patrocinados, na maior parte, pela iniciativa privada. Ganham espaço os curadores e as atividades pedagógicas voltadas para o público de massa.

Palavras-chave: cultura; bienal; arte; artes plásticas; política cultural.
\end{abstract}

$\mathrm{E}$ m 20 de outubro de 1951 a Av. Paulista vivia um dia marcante na sua história. A festa de abertura da primeira Bienal de São Paulo reunia a nata da elite política, econômica e cultural do país. Do lado de fora do Edifício Trianon (onde hoje, coincidentemente, encontra-se o Masp), militantes políticos e sindicalistas bradavam contra aquilo que chamavam de manobra imperialista e verdadeira farra de tubarões. Sob a conhecida garoa paulistana, os manifestantes e curiosos assistiam ao desfile da granfinagem (Jornal Hoje, 02/09/1951 e 21/ 10/1951), enquanto os bancários exibiam suas tabuletas nas quais se lia: Chega de fome! Viva a greve! Do lado de dentro do edifício, Francisco Matarazzo Sobrinho e Yolanda Penteado, sua esposa, comandavam a festa oferecida a milhares de convidados, ciceroneando o Ministro da Educação e Saúde, o sr. Simões Filho, e a sra. Vargas, ambos representantes do Presidente da República.

O principal ponto de discórdia entre esses dois lados recaía sobre Nelson Rockefeller, o magnata do petróleo e peça-chave na política de expansionismo cultural do Departamento de Estado norte-americano no pós-guerra. Poucos dias antes da abertura da Bienal de São Paulo, Yolanda Penteado havia promovido um baile no próprio Edifício Trianon, com a intenção de arrecadar fundos para o evento do MAM. Os jornais noticiaram a festa dançante, dando destaque ao presidente da Standard Oil enlaçado à anfitriã brasileira. A imagem simbolizava uma união de parceiros que surgia juntamente com uma nova etapa no desenvolvimento capitalista, na qual a internacionalização do capital começava a despontar liderada pelos Estados Unidos, fazendo-se acompanhar pelo surgimento de um mercado internacional de arte (Bueno, 1999). Para aqueles que protestavam na entrada da bienal naquela chuvosa noite de outubro, a parceria estabelecida entre Rockefeller e Ciccilo Matarazzo representava a força do imperialismo corrompendo pintores, desenhistas, escultores e arquitetos com prêmios oferecidos por empresas interessadas na expansão ideológica americana (Jornal Voz Operária, 13/10/1951). Para o proprietário da Metalúrgica Matarazzo, o estreitamento das relações econômicas, culturais e, no limite, políticas, entre Brasil e Estados Unidos poderia significar um espaço diferenciado a ser ocupado por um empresário-mecenas atuante internacionalmente.

O momento era pontuado por importantes transformações em toda a América Latina. O final da Segunda Guerra anunciava novos horizontes econômicos, políticos, intelectuais e artísticos. Um novo ordenamento mundial e novas relações políticas articulavam-se a uma nova postura das classes dirigentes, assim como de intelectuais e artistas. Estavam sendo deixadas para trás as décadas fundamentadas no desenvolvimento nacional, com um projeto nacional e por uma burguesia também nacional. No pósguerra, o jogo das forças internacionais tem suas regras 
alteradas e o capitalismo passa a propor o desenvolvimento transnacional ou associado.

Dentro desse contexto, a cidade de São Paulo vislumbrava um cenário favorável ao seu desenvolvimento econômico e cultural. No início da década de 50 a cidade já registrava a maior concentração de brasileiros vindos de outros Estados e também já abrigava expressivo contingente de imigrantes, inclusive daqueles estrangeiros que para cá se dirigiam para instalar seus negócios, fábricas e empresas, fugindo das catástrofes econômicas e sociais do pós-guerra europeu (Pedrosa, 1995:220). Com o surto de industrialização impulsionado pela substituição de importações, a população urbana teve um brutal crescimento e a população operária mais que dobrou entre 1940 e 1950. São Paulo acelerava sua ascensão econômica e industrial como síntese do Brasil e vitrine do mundo.

A precariedade da indústria cultural brasileira deu lugar ao processo de modernização dos meios de comunicação de massa, que passaram a desempenhar um papel fundamental na busca de integração nacional. A consolidação de uma sociedade urbano-industrial fez-se acompanhar de um amadurecimento e uma ampliação de um mercado de bens simbólicos (Ortiz, 1991:43-49). Do ponto de vista cultural, o rádio consolidou-se como veículo de massa; o cinema tornou-se, de fato, um bem de consumo; o mercado de publicações ampliou-se com o maior número de jornais, revistas e livros; a publicidade foi dinamizada com a introdução das multinacionais no país.

Impunha-se, especialmente em São Paulo, uma linguagem metropolitana (Arruda, 2000). Buscava-se ampliar a adesão ao novo estilo urbano que exercia pressão, permeado pela afirmação do progresso recém-iniciado, em que o presente e o futuro importavam mais que o passado.

Entre a aceleração cosmopolita vivida em São Paulo e os reais avanços culturais havia um imenso abismo e a Bienal de São Paulo surgia como um ponto de equilíbrio. Os seus criadores buscavam estimular os avanços na produção artística nacional, mas não escondiam o fato de que um evento como esse só poderia acontecer num ambiente semeado pelo espírito da modernização. No catálogo de apresentação da primeira bienal, o Ministro da Educação e Saúde já destacava que São Paulo seria "a terra predestinada aos ímpetos da evolução brasileira”, por ser o “centro natural do modernismo brasileiro e do progresso industrial” (Simões Filho, 1951:10). Segundo Lourival Gomes Machado, diretor do MAM-SP e diretor artístico da mostra, a bienal deveria cumprir duas tarefas: "colocar a arte moderna do Brasil, não em simples confronto, mas em vivo contato com a arte do resto do mundo, ao mesmo tempo que para São Paulo se buscaria conquistar a posição de centro artístico mundial" (Machado, 1951:14), tendo como referência a cidade de Veneza. Esse espírito de modernização que permeava a realização da bienal envolvia uma disputa pela hegemonia entre Rio e São Paulo. Na primeira, a capital da República, as iniciativas vinham basicamente do Estado; já na segunda, principal sede do surto de crescimento industrial e demográfico, as coisas começavam a se fazer por intermédio de particulares (Pedrosa, 1995:239), representantes de uma nova prática cultural que emergia com as transformações pelas quais a cidade passava.

Naquele momento, realizar uma bienal significava colocar a cidade de São Paulo no patamar das práticas sociais vividas pelas nações modernas. A bienal nasce, portanto, como um produto cultural construído a partir das relações entre determinados produtores culturais, instituídos a partir de relações sociais. Essas práticas sociais envolvem a vida econômica, o cotidiano da metrópole, a formação de uma nação tipicamente moderna e a intenção de acompanhar as práticas metropolitanas internacionais.

\section{O PÓS-GUERRA EM SÃO PAULO}

Os novos empreendimentos culturais na capital paulista foram sustentados por um novo mecenato, proveniente dos setores emergentes da sociedade: a indústria e as organizações da imprensa. Nos anos 20 e 30, os escritores e pintores modernistas haviam sido 'adotados' pela burguesia local, principalmente pelas famílias Prado, Penteado e Freitas Valle. Nessa adoção, pretendiam repetir nas suas mansões o modelo dos salões literários franceses descritos por Marcel Proust. Empenhavam-se numa tarefa civilizadora, numa São Paulo ainda provinciana. Já nos anos 40 a relação entre a produção artística e o mecenato seria bem diferente. A atmosfera dos salões seria deixada de lado em nome da criação de uma série de instituições artísticas bastante internacionalizadas. Esses novos personagens do fomento cultural localizavam-se num pequeno grupo de burgueses, fruto de uma mistura da antiga elite da terra e de uma elite mais recente de origem italiana. Segundo Maria Arminda do Nascimento Arruda, esse processo foi um "sintoma de deslocamento, ou perda de exclusividade dos grupos tradicionais e, de toda espécie, manifestação insofismável de transformação das atividades produtivas (Arruda, 2000:33). Essa camada emergente passava a financiar a cultura em empreendimentos 
conectados a um movimento de ascensão e de busca de legitimidade. A velha intelectualidade oficial burguesa incorporava uma nova intelectualidade surgida no seio da classe média, especialmente por meio daquela formada na década de 40 pela USP. Esse novo mecenato, diversamente daquele característico dos anos 20 e 30, dirigiu-se para a criação de instituições, alterando as bases dessa atividade e da vida cultural paulistana. As atividades culturais passaram a usufruir, de diversas maneiras, da presença dessas instituições.

Dois empresários paulistas começaram, no pós-guerra, a descobrir os caminhos de um certo mecenato moderno: de um lado, Assis Chateaubriand (1891-1968), empresário ligado às comunicações que se embrenhou pelos trâmites artísticos; do outro, Francisco Matarazzo Sobrinho (1898-1977), o Ciccilo, industrial de ascendência italiana, hoje considerado Presidente Perpétuo da Fundação Bienal. Chateaubriand e Ciccilo acrescentaram aos seus dotes empresariais uma atitude de mecenas que os fez entrar para a história deste país com esta marca. As disputas entre esses dois empresários, afeitos ao mecenato, tornaram-se quase um folclore na cidade de São Paulo. Ambos apareceram como um novo tipo de empresariado que buscava se projetar no mundo econômico através dos empreendimentos culturais de cunho internacional.

Ciccilo Matarazzo era sobrinho do Conde Francisco Matarazzo, italiano que construiu um dos maiores complexos industriais do Brasil. Francisco Matarazzo Sobrinho nasceu em 1898, em São Paulo, na rua Major Quedinho. Estudou no conceituado Instituto de Educação Caetano de Campos, na Praça da República, mas em 1908 foi enviado a Nápoles, acompanhado de um preceptor, a fim de completar o ensino médio. Depois seguiu para Liège, na Bélgica, onde cursou engenharia na universidade local. Viveu na Europa entre os 10 e os 20 anos, recebendo formação humanística da belle époque. Por conta desses anos vividos na Europa e da forte ascendência italiana, seu sotaque ficaria marcado para o resto da sua vida, com uma mistura de italiano e francês ao falar o português. Nessa época gostava de pinturas, mas seu gosto estava apegado ao estilo acadêmico. Ciccilo deixava-se atrair mais por "uma Bugatti reluzente ou uma Fiat modelo esportivo" (Almeida, 1976:20) do que pelas artes.

O pós-guerra abria caminho para o fortalecimento institucional e a atuação desse novo mecenato cultural e, em 1948, Ciccilo Matarazzo e Franco Zampari fundaram o Teatro Brasileiro de Comédia (TBC). O engenheiro Zampari era amigo de infância, compatriota e funcioná- rio de Ciccilo. Dentre tantos outros empreendimentos culturais construídos por estrangeiros já aclimatados, "o TBC acabou sendo reconhecido como símbolo da cidade" (Arruda, 2000:138). No ano seguinte, Ciccilo Matarazzo fundou a Cia. Cinematográfica Vera Cruz, também em parceria com Zampari. Desde o início, a Vera Cruz foi um projeto da burguesia paulista de criação de um cinema de qualidade no país. A dupla de origem italiana sonhava trazer para o ABC paulista a posição ostentada pela carioca Atlântida. Para dar início ao projeto, Ciccilo cedeu parte do terreno de sua granja, em São Bernardo do Campo (hoje Jardim do Mar), para erguer os estúdios da Cia. Cinematográfica, que durou até 1954.

A criação do TBC e da Vera Cruz não foi um fenômeno isolado. Pelo contrário, eles inscreveram-se em outras iniciativas que procuravam fazer de São Paulo um pólo cultural, contribuindo para transformar esta capital, no final dos anos 40, num importante centro de produção de cultura. Em 1947, Chatô havia inaugurado o Masp e destacava-se como empresário da cultura que acenava para algo novo: o empreendimento cultural como uma forma de luta hegemônica. Ciccilo também fundou 'seu' museu, o de Arte Moderna, no ano seguinte. Em 1951, como extensão das atividades do MAM, Ciccilo criou o seu mais poderoso empreendimento: a Bienal de São Paulo.

As primeiras bienais contaram com o esforço de Yolanda Penteado, esposa de Ciccilo na época. D. Yolanda pertencia a uma tradicional família paulista que construiu sua fortuna a partir da cultura do café (Penteado, 1976). Nasceu em 1903, na Fazenda Empyreo, em Leme, interior de São Paulo. Foi criada num ambiente de senhores de escravos e teve, durante sua infância, muitas mães-pretas. Viveu até os sete anos na fazenda e depois mudou-se com a família para São Paulo. Seu pai era amigo de Júlio Mesquita e de Antônio da Silva Telles, pai de Jayme Telles (o 'Rodolfo Valentino') com quem Yolanda viria a se casar mais tarde. Assim como Ciccilo, Yolanda também estudou no Caetano de Campos e, depois, como interna, no Colégio Des Oiseaux, onde só se falava francês. Mais tarde passou a estudar em casa, com professores particulares.

Era sobrinha de dona Olívia Guedes Penteado, que nos anos 20 e 30 freqüentava os salões de Freitas Valle e costumava também acolher em sua casa artistas modernistas. Entretanto, Yolanda Penteado teve, aparentemente, pouco contato com essas rodas artísticas e com a arte moderna, pois não menciona isso em sua autobiografia. Sua juventude foi marcada pelo interesse que despertava nas pessoas ao seu redor. Jovem, bonita, culta e alegre, 
Yolanda colecionava uma legião de fãs, entre eles Júlio Mesquita Filho, Alberto Santos Dumont e, principalmente, Assis Chateaubriand, que a teria pedido em casamento várias vezes. Ela dedica muitas passagens de sua autobiografia a ele, a quem se refere como o melhor amigo que já tivera. No decorrer de sua vida, a roda de amizades de Yolanda Penteado incluiu Getúlio Vargas, Oswald de Andrade, Tarsila do Amaral, Di Cavalcanti, Maria Martins e Gilberto Freyre.

Separou-se de Jaime Telles em 1934 e, com 30 anos e sozinha, tornou-se responsável pela Fazenda Empyreo. Por lá passaram alguns dos principais personagens do cenário artístico, intelectual, político e econômico do país. Yolanda Penteado sabia receber e o fazia muitíssimo bem, especialmente em sua fazenda. Durante as primeiras bienais, por exemplo, ela organizou inúmeros jantares para os convidados especiais do evento. A abertura da IV Bienal de São Paulo (1957) deu-se na fazenda de Leme, com os convidados transportados em aviões que pousavam na pista construída nas terras de Yolanda e depois cedida ao poder público municipal. Naquela noite, o principal convidado era o presidente Juscelino Kubitsckek, que jantou e pernoitou no local.

\section{MUSEU DE ARTE MODERNA}

Yolanda Penteado casou-se com Ciccilo em 1947, enquanto estavam em Roma. De lá partiram para Paris, onde Ciccilo adoeceu. Por recomendação médica, foram passar uma temporada de sete meses em Davos, no sanatório Schatzalp, onde ocuparam o melhor quarto. Durante esse período, conviveram com pessoas que lhes revelaram o mundo das artes e atuaram de forma definitiva na fundação do Museu de Arte Moderna de São Paulo. Ciccilo registrou apenas que já planejava a organização de um museu por ocasião de sua estadia no sanatório (Penteado, 1976:34). Lá conheceu o museólogo Karl Nierendorf, diretor do Museu Guggenheim, com quem idealizou a montagem de uma exposição de arte abstrata para a abertura do museu paulistano. Nierendorf, com quem tinha uma convivência diária no cenário de Montanha Mágica, havia pertencido à Bauhaus e durante a guerra tinha ido para os Estados Unidos, onde lidou com arte e freqüentava as rodas modernistas.

Pelo contato com Nierendorf, foi estabelecido um acordo entre Ciccilo Matarazzo, responsável pelo MAM-SP e Nelson Rockefeller, da Standard Oil, estabelecendo a fusão das atividades do museu paulista e do Museu de Arte
Moderna de Nova York (Jornal Hoje, 15/08/1951). Mas as relações com Rockefeller para a criação do MAM de São Paulo já tinham sido iniciadas anos antes de Ciccilo atentar para essa questão, e diziam respeito às articulações do envolvimento do Brasil nas transformações da economia mundial.

Entre o final dos anos 30 e o início dos 40, Sérgio Milliet, como professor da Escola de Sociologia e Política, esteve em contato com representantes americanos interessados na política de aproximação com os países latino-americanos. Em 1942, o dr. David Stevens, diretor da Divisão de Humanidades da Fundação Rockefeller, visitou a Escola e doou cinco contos de réis destinados à constituição de um acervo bibliográfico e à pesquisa social, repetindo a atitude em 1944 e 1946 . O adido cultural do Consulado Americano em São Paulo, Carleton Sprague Smith, era também professor na Escola de Sociologia e Política e empolgava-se, àquela altura, com a idéia da criação de um museu de arte moderna, acabando por tornarse um intermediário desse processo com a Fundação Rockefeller (Gonçalves, 1992:80). Segundo Lisbeth Gonçalves, São Paulo recebeu, em 1946, a primeira doação de Nelson Rockefeller para a constituição de um museu, num total de sete obras que ficaram sob a guarda do Instituto dos Arquitetos do Brasil (IAB), ${ }^{1}$ mas que permaneceram na Biblioteca Municipal, provavelmente na Seção de Arte criada por Milliet no ano anterior (Gonçalves, 1992:81). A partir desse momento, cresceu rapidamente o número daqueles que apoiavam o projeto do museu, envolvendo arquitetos, jornalistas, intelectuais e artistas que se encontravam nas sucessivas reuniões no Instituto dos Arquitetos. Chateaubriand e Ciccilo também aderem ao projeto, participando das reuniões no IAB. A partir do aval americano, Matarazzo passou a encabeçar a lista daqueles que apoiavam essa idéia. Segundo Vilanova Artigas, em depoimento à Lisbeth Gonçalves (1992:82):

"A palavra final que leva ao encaminhamento do processo de criação do Museu de Arte Moderna de São Paulo sob a liderança de Matarazzo surge numa reunião de Nova York, da qual ele participa, quando bolsista nos Estados Unidos. Carleton Sprague Smith é o porta-voz de Rockefeller, falando do seu interesse pela participação daquele empresário no projeto".

Esse novo tipo de mecenato representado por Ciccilo Matarazzo surge num período de expansão do capitalismo internacional que exigiu mudanças também na atuação dos representantes da burguesia local, a qual passou a adotar uma posição aberta à penetração das grandes cor- 
porações estrangeiras (Fernandes, 1975). Com isso a burguesia ganhou condições mais vantajosas para estabelecer uma relação mais íntima com o capitalismo financeiro internacional, sustentando-se sobre uma base nacional e outra internacional. Essa burguesia mudou seu relacionamento com o poder político estatal e o funcionamento do Estado, alterando sua capacidade de aproximação com o capital financeiro internacional e com a intervenção do Estado na vida econômica, ganhando maior controle da situação interna. As grandes corporações, por outro lado, passaram a concorrer fortemente entre si pela expansão induzida das chamadas economias periféricas. Foi nesse contexto que se deu a aproximação entre Ciccilo Matarazzo e a Fundação Rockefeller. No momento em que o capitalismo monopolista investia suas energias nas nações do continente latino-americano, a burguesia mudava sua estratégia com relação ao poder político e passava a atuar visando o capital internacional.

O MAM de São Paulo foi uma das instituições organizadas a partir desse estreitamento das relações entre a burguesia industrial brasileira e as grandes corporações norte-americanas. Fundado em 1948, mas inaugurado em março de 1949, o MAM chamou para si toda a polêmica que girava em torno da ascendente arte abstrata, organizando, para a sua abertura, a mostra Do figurativismo ao abstracionismo que, apesar do nome, só trazia trabalhos abstracionistas.

Tanto o MAM quanto o Masp carregavam consigo promessas civilizatórias relativas às "ações de grupos esclarecidos da classe dominante, ou dos seus representantes, que desenvolviam uma pedagogia em relação à sociedade, tendo em vista educá-la" (Arruda, 2000:280). Esses dois museus de arte paulistanos foram criados numa conjuntura tensa, num momento fervilhante de debates em que artistas, intelectuais e escritores, polarizavam-se em torno das polêmicas sobre a cultura de participação da arte social, base dos conflitos entre novas e antigas gerações que desaguavam na questão do realismo e abstracionismo.

\section{A BIENAL DE SÃo PAULO}

A organização de uma mostra bienal - ou um festival nos moldes do festival de Veneza, como afirmou Ibiapaba Martins, um dos diretores do recém-fundado museu (apud Amaral, 1987:236) - já estava nos planos de Ciccilo desde os primeiros momentos do MAM. Se a meta era a internacionalização, o melhor caminho seria a criação de uma bienal. A Bienal de São Paulo surgiu, assim, como uma extensão do MAM e completando sua função, que era a de fornecer, como em Veneza, uma possibilidade de iniciação às novas correntes de arte. Um esforço conjunto tentava ligar a América Latina ao circuito internacional de arte e a bienal funcionou como um mecanismo de divulgação e consolidação da arte moderna e do campo artístico internacional (Bueno, 1999:151).

Para dar conta dessa empreitada, Yolanda Matarazzo viajou por toda a Europa juntamente com a escultora Maria Martins em caráter semi-oficial e com o apoio irrestrito de Getúlio Vargas, que telegrafara às embaixadas brasileiras pedindo que fosse dado todo apoio às duas senhoras (Penteado, 1976:178). A I Bienal do Museu de Arte Moderna de São Paulo, presidida por Francisco Matarazzo Sobrinho, foi considerada um sucesso e colaborou para a sedimentação do museu como uma instituição cultural alinhada ao mercado artístico internacional.

Mas o sucesso e a continuidade da bienal devem-se, em grande medida, às atuações de Sérgio Milliet e Lourival Gomes Machado à frente da diretoria artística do evento durante suas primeiras edições. Os anos 40 viam entrar em cena uma nova crítica de arte decorrente da institucionalização da vida universitária que exalava principalmente da USP (Pontes, 1998). Dentro da nova linguagem metropolitana que ganhava espaço em São Paulo, a crítica de arte sofria transformações pela atuação de jovens intelectuais recém-saídos da Faculdade de Filosofia, inaugurando um novo sistema de produção intelectual totalmente firmado em critérios científicos e acadêmicos.

$O$ estilo acadêmico de cultura passa a constituir um estilo de vida. O saber científico é visto como o fundamento da dignidade e do prestígio profissional. O conhecimento, enfim, começa a exigir novos requisitos: a produção norteada pelos cânones científicos, as reflexões apoiadas em exaustivas referências bibliográficas e erudições pertinentes ao campo da investigação. Nos anos 40 e 50, ao contrário do que ocorria com as gerações passadas, a elaboração de idéias e a atividade intelectual sofriam os rigores das exigências acadêmicas.

A presença de Lourival Gomes Machado (1917-1967), na época, diretor do MAM, foi fundamental para o sucesso da primeira edição da Bienal de São Paulo, em 1951. Como diretor artístico do evento, adaptou o regulamento da Bienal de Veneza às características nacionais e supervisionou a montagem das instalações e seleção das obras. Sua carreira de crítico de artes plásticas teve origem no seio da academia, mas foi como diretor da revista Clima, lançada em maio de 1944, que se notabilizou na área, pas- 
sando a constituir essa nova geração de críticos ligados ao conhecimento acadêmico. Lourival Gomes Machado foi o primeiro diretor artístico da Bienal de São Paulo e, sem dúvida, um dos principais mentores do evento e dos mais atuantes na sua implantação.

Sérgio Milliet (1898-1966) foi primeiro-secretário na I Bienal e a partir da segunda substituiu Lourival Gomes Machado na diretoria artística. Citando Antônio Cândido, Lisbeth Gonçalves considera Milliet o homem-ponte entre a geração modernista e a geração de artistas que surgiram nas décadas de 30 e 40. Milliet era "consciente defensor da criação de entidades voltadas para a ação organizada em prol da arte moderna na cidade" (Gonçalves, 1992:XV) e por isso seu nome liga-se à criação do Departamento de Cultura, da Biblioteca Municipal, do Museu de Arte Moderna e da bienal. Milliet nasceu em São Paulo, adquiriu conhecimentos de sociologia em Genebra e Berna em longos anos de educação suíça, impregnando-se de discussões acerca da verdade e da objetividade que ocupavam todo o pensamento europeu a partir do reconhecimento do valor da ciência para o conhecimento da realidade. Assim, como crítico, trazia a sociologia como principal eixo de reflexão. A partir da aproximação das posições do cristianismo social ou socialismo cristão que proliferavam na Suíça durante os anos em que lá morou, Sérgio Milliet foi mais tarde tocado diretamente pela questão engajamento/não-engajamento e o papel do intelectual no seu tempo. No Brasil dos anos 30 foi um dos primeiros a aderir ao Partido Socialista, tendo inclusive participado da Revolução de 1932 como informante (Gonçalves, 1992:20 e 57). Nas noites paulistanas passou a freqüentar a casa de Paulo Duarte, onde conviveu intensamente com intelectuais e políticos de tendência liberal, em encontros que resultaram na idealização do Departamento de Cultura dirigido nos anos 30 por Mário de Andrade. No Departamento de Cultura Milliet atuou como diretor da Divisão de Documentação Histórica e Social. No início dos anos 40, já sob a intervenção do Estado Novo na prefeitura paulistana, Milliet foi transferido para a Divisão de Bibliotecas, vindo a atuar na Biblioteca Municipal, onde criou a Seção de Arte em 1945. Essa seção da Biblioteca Mário de Andrade, que hoje se chama Sérgio Milliet, surgiu da necessidade de se erguer instituições voltadas para a arte moderna na cidade e fundamentadas por ações mais organizadas. Desde o final dos anos 30, Milliet e Mário de Andrade anunciavam a necessidade da criação de um museu de arte moderna em São Paulo. Foi na Biblioteca, com a Seção de Arte organizada por Milliet, que se iniciaram as bases essenciais para a criação do MAM.

Ao mesmo tempo em que atuava na prefeitura, Milliet colaborava na Escola de Sociologia e Política desde sua abertura, primeiro como secretário, depois como professor e tesoureiro. Ao longo da década de 50, o projeto de Sérgio Milliet reforçou o internacionalismo na arte, movimento que já vinha se manifestando de modo gradativo em eventos anteriores mesmo às bienais, entre os quais os Salões de Maio e o advento dos museus em São Paulo. Milliet trouxe para a crítica o cosmopolitismo de sua formação européia: nunca assumiu a ótica da 'cultura nacional' e nunca se prostrou em reverência pelo que era importado. Era um polivalente que escrevia com igual propriedade de conhecimentos sobre literatura e artes visuais, sociologia e política, filosofia e psicologia. Com gosto pelas viagens e atento, Milliet inaugurou um novo perfil profissional no meio até então dominado por bacharéis apegados a frases rebuscadas, egressos da advocacia ou da medicina, no geral contrários às novas linguagens.

A II Bienal do museu, realizada em 1953, aconteceu sob a direção artística de Milliet e pegou uma carona no ritual de celebração do IV Centenário da cidade de São Paulo. Mais conhecida como a Bienal da Guernica, aquela edição nunca foi superada em importância e respeito. Milliet atuou ainda como diretor artístico na terceira e quarta bienais realizadas pelo Museu de Arte Moderna (1955 e 1957), colaborando de maneira fundamental para a sedimentação e continuidade deste evento que estava inserindo a cidade de São Paulo no seleto circuito internacional de arte. Nos anos em que esteve à frente da diretoria artística da bienal, Milliet deixou transparecer, mais uma vez, a característica pedagógica que marcou sua atuação como crítico de arte, privilegiando a preocupação com a formação e informação dos artistas e do público, com a educação do gosto da comunidade, de modo a abrir condições para o diálogo com a arte do presente (Gonçalves, 1992:87). De uma certa forma, essa preocupação pedagógica estaria presente em toda a história da Bienal de São Paulo, chegando ao final do século XX como um dos seus principais pontos de apoio.

Em 1959, a V Bienal voltou a contar com Lourival Gomes Machado à frente da direção artística. Essa foi a última bienal realizada pelo MAM; a partir da VI edição, a mostra passou a ser organizada pela Fundação Bienal. Em 1961, a bienal passou a ser uma entidade autônoma com a autorização do presidente Jânio Quadros ao crítico Mário Pedrosa, então secretário do Conselho Nacional de 
Cultura, para que a tornasse uma instituição pública a partir da redação um projeto de lei (Amarante, 1989:106). Transformada em Fundação, a Bienal de São Paulo poderia passar a receber verbas da prefeitura e do governo do Estado para a execução da exposição. Até então, as exposições do Ibirapuera eram financiadas basicamente - e oficialmente - pela iniciativa privada.

A VI Bienal (1961) comemorou os dez anos de bienais com o crítico Mário Pedrosa como diretor-geral, mas foi apenas na sétima edição (1963) que a bienal ocorreu definitivamente desvinculada do MAM, mas ainda sob a presidência de Ciccilo Matarazzo. Quatro meses após o término dessa bienal os militares tomariam o poder no Brasil e, daí para frente, a Fundação Bienal começa a entrar numa outra etapa de sua existência.

A edição de 1967 (IX Bienal) foi a Bienal Pop, nas palavras de Liliana H. T. Mendes de Oliveira (1993). As categorias tradicionais de classificação das obras de arte (pintura, escultura, desenho e gravura) já não mais comportavam as obras de última geração e o regulamento foi alterado de modo a permitir as inovações radicais que estavam em plena expansão (Pedrosa, 1995:273), como a arte cinética de Júlio Le Parc, por exemplo. No mesmo ano em que a censura apenas começava a mostrar suas garras, a pop art americana chegava ao público brasileiro através de uma sala especial com a participação de Hooper, Warhol, Rauschenberg e Lichtenstein.

A partir da X edição (1969), a pressão da ditadura militar começou a aumentar. Financiada agora pelo poder público, a Bienal de São Paulo começava a entrar num longo período de decadência de seu prestígio internacional. A censura e os conseqüentes boicotes por parte de delegações estrangeiras esvaziavam paulatinamente a bienal.

Em 1975, por ocasião da XIII Bienal, Ciccilo não mais exercia controle total sobre a Fundação. Doente, pediria demissão naquele mesmo ano. Dois anos depois, a Fundação Bienal organizava sua primeira mostra sem o seu fundador, que morrera seis meses antes. Oscar Landmann seria o primeiro presidente da Fundação Bienal depois da Era Ciccilo. A partir desse momento, as bienais passariam a ter a cara de seus presidentes e a história da Fundação Bienal passaria a ser a história da sucessão desses homens.

A Fundação Bienal viu a década de 80 chegar, tendo de enfrentar sérios problemas para se sustentar. Com a abertura política e a mudança nas relações dos poderes público e privado com a cultura, a forma de financiamen- to da Fundação Bienal passaria por uma drástica transformação, especialmente por conta do expressivo aumento da participação da iniciativa privada no patrocínio da mostra. Transformações rápidas estavam começando a acontecer, especialmente na estrutura da Bienal, envolvendo, além da forma de financiamento, também o final das premiações. Era um momento de tentativa de desvinculação do oficialismo e do surgimento dos curadores como produtores. Essas mudanças, sem dúvida, vão aparecer mais concretamente na segunda metade dos anos 80 .

Em 1981, com o industrial Luiz Villares como presidente e Walter Zanini como curador, a XVI Bienal foi um marco na história desse evento e o início da retomada do prestígio internacional. A forma de organizar a mostra mudou, abandonou-se a montagem com separações por países e introduziu-se o trabalho curatorial baseado em analogias de linguagem. Saía de cena o poder público como o principal patrocinador das exposições bienais e entrava em jogo a iniciativa privada, que descobria o marketing cultural como uma forma de associar sua imagem a projetos culturais de cunho internacional. Na edição de 1983 , também sob a responsabilidade da dupla Villares/Zanini, $50 \%$ do orçamento do evento derivara da contribuição da iniciativa privada (Villares, 1983:3). Roberto Muylaert, Jorge Wilheim e Alex Periscinoto, presidentes da Fundação Bienal entre a XVIII e XX bienais, buscaram aprofundar essa participação da iniciativa privada e o desvinculamento dos trâmites oficiais.

A XXI Bienal de São Paulo, realizada em 1991 sob a presidência de Jorge Stocker, foi bastante polêmica. O regulamento fez retornar a seleção das obras a partir de um júri e foi reinstituída a premiação. Após esse breve retorno a alguns princípios tradicionais na organização do evento, a XXII e a XXIII bienais (1994 e 1996), lideradas pelo banqueiro Edemar Cid Ferreira e pelo curador Nelson Aguilar, fizeram intensificar pesadamente os investimentos da iniciativa privada e o trabalho curatorial na organização do evento. Com o segmento Universalis, evidenciava-se a "abolição da inércia de tentativas anteriores, nas quais a instituição era mera hospedeira de representações nacionais" (Ferreira, 1996:17). Era a retomada da proposta de Walter Zanini e a confirmação de que a atuação do curador tornava-se cada vez mais importante.

Em 1998, o industrial Júlio Landmann e o curador Paulo Herkenhoff organizaram a XXIV Bienal de São Paulo, considerada pela revista Artforum (2000) como uma das dez exposições mais importantes da década de $90 \mathrm{em}$ todo o mundo. Com essa edição, a Bienal de São Paulo chegou 
ao final do século como uma mostra renovada e bastante reconhecida no circuito internacional de arte, com um público de quase 500 mil pessoas e orçamento de $12 \mathrm{mi}$ lhões de dólares.

Os pesados investimentos da iniciativa privada colaboraram para que o maior evento das artes plásticas no Brasil chegasse à beira de completar cinco décadas de existência cumprindo um dos objetivos propostos desde o seu início, em 1951: apresentar-se como uma exposição de massa. Apesar do que se pode pensar num primeiro momento, a Bienal de São Paulo não é um evento restrito à esfera da cultura erudita ou letrada, mas sim um produto cultural que mescla cuidadosamente elementos populares e massivos da cultura àqueles típicos de uma cultura dita elevada. Assim como as Exposições Universais do século XIX europeu, a Bienal de São Paulo, seguindo o exemplo de Veneza, sempre pretendeu portar-se como um canal para os ideais civilizatórios, ligado ao poder das nações hegemônicas.

Nesse processo, novas instâncias de decisão foram surgindo e novos atores foram ganhando destaque, na medida em que a divisão do trabalho foi incorporando a especialização das funções na sua produção. No final dos anos 90, a produção da Bienal de São Paulo envolveu um complexo processo coletivo de criação compreendendo o presidente, os curadores, arquitetos, diretores e montadores. As articulações institucionais e financeiras transformaramse numa verdadeira 'força-tarefa' para erguer um evento desse porte. A investigação dos propósitos e dos caminhos tomados nessa produção revela um determinado formato pretendido por esses agentes espalhados por diversos níveis de decisão dentro da instituição.

\section{A VEZ DOS CURADORES}

Se nas primeiras bienais os diretores artísticos e os montadores responsabilizavam-se pelo conjunto da exposição, nas últimas edições vimos surgir cada vez mais evidente a figura do curador. Hoje em dia, os curadores são, muitas vezes, os principais produtores dessas grandes mostras. Para Teixeira Coelho (2000:251) "quando vamos a uma exposição hoje, uma exposição dessas que têm linha, tema, vamos ver antes o trabalho de um supra-artista, o curador, do que o trabalho de vários artistas que fazem cada um sua obra. Os artistas, estes, são instrumentos para o curador. O curador é o grande artista”. Embora nem sempre o grande público se dê conta, por trás das exposições de arte "existe todo um trabalho conceitual e opera- cional, envolvendo profissionais das mais diversas áreas encabeçados, costumeiramente, pela figura do curador" (Chiarelli, 1998:32). Até os anos 70, os curadores estavam basicamente ligados à atividade museológica de lida com o acervo e sua função não era muito bem definida, confundindo-se com a figura do diretor do museu, responsável também pela gestão administrativa e articulações políticas. Entretanto, as grandes exposições comemorativas ou os grandes eventos artísticos, como a bienal, por exemplo, já possuíam seus curadores que, com pouca notoriedade, eram conhecidos como operadores culturais. No caso da bienal isso passou a acontecer especialmente a partir de 1977, quando o Conselho de Arte e Cultura foi criado, mesmo ano em que Ciccilo faleceu. Tadeu Chiarelli (1998:14), ex-curador do MAM-SP, aponta: "Com o processo de espetacularização destes eventos - que a cada edição tornavam-se mais e mais impressionantes pela quantidade de obras, pelo caráter cenográfico e espetacular a figura do curador convidado a concebê-la e organizá-la foi aos poucos ganhando um destaque cada vez maior, em alguns casos chegando a ofuscar as obras e os artistas participantes da mostra".

A transformação do papel do curador acompanhou as mudanças ocorridas na atividade museológica principalmente a partir dos anos 80, quando a explosão de público na Europa e nos EUA apontou a mudança dessas instituições e suas atividades. A museumania, segundo Andreas Huyssen (1997:223), incorpora definitivamente os museus à cultura de massa:

"O papel do museu como um local conservador elitista ou como um bastião da tradição da ata cultura dá lugar ao museu como cultura de massa, como um lugar de um miseen-scène espetacular e de exuberância operística”.

Para Huyssen (1997:232), “'curar' hoje não significa desempenhar a função de 'guardião' de coleções (...) mas significa mobilizar coleções, colocá-las em ação nas paredes dos museus particulares". Nessa mobilização das obras, o trabalho do curador envolve sempre uma atividade reflexiva e interpretativa. No seu trabalho, o curador opta sempre por uma narrativa que alinhave a exposição.

Na XXIV Bienal de São Paulo (1998) um dos principais nomes, sem dúvida, foi Paulo Herkenhoff, curadorgeral da mostra. Sob o tema Antropofagia, Herkenhoff buscou organizar a mostra a partir do público que a visitaria, tentando, nas suas palavras, torná-la mais legível e assimilável (apud Fioravante, 1998) para cada um dos milhares de visitantes da exposição. 
A estrutura formal de organização do evento não sofreu muitas alterações com relação à mostra de 1996 e foi dividida em quatro segmentos: o tradicional Representações nacionais, que, à exemplo da Bienal de Veneza, recebe os trabalhos enviados a partir de relações diplomáticas entre o Brasil e dezenas de países participantes; o Núcleo histórico, dedicado a discutir o tema Antropofagia e histórias de canibalismos e tem sido de extrema importância para a captação de recursos da iniciativa privada pela atração que exerce perante o grande público; o segmento Roteiros, roteiros, roteiros, roteiros, roteiros, roteiros, roteiros, uma mostra internacional de arte contemporânea realizada nos moldes do segmento Universalis da Bienal de 1996, fundamentalmente baseada no forte trabalho curatorial; e, por fim, o segmento Arte contemporânea brasileira, uma novidade na história do certame brasileiro que foi proposta por Júlio Landmann, presidente da Fundação Bienal.

As bienais paulistanas, pode-se dizer, não são apenas eventos dirigidos às massas, mas também um novo modo de comunicação entre as classes, e por isso recebe em seu formato as marcas dessa negociação conflituosa que se dá no campo das lutas hegemônicas. A Bienal de São Paulo teve seu formato transformado ao longo dos seus quase 50 anos devido às diversas estratégias utilizadas para a viabilização da sua produção. Até um determinado momento, essas estratégias exigiram a força das representações nacionais, organizadas a partir de relações diplomáticas; mas, para continuar existindo como uma mostra importante para sua época, a Fundação Bienal teve de mudar as regras do jogo, transformando o formato da mostra. No final dos anos 90, o necessário apoio governamental e diplomático inviabilizou a extinção total das delegações nacionais; a busca do público massivo impediu que os curadores apostassem apenas na arte contemporânea e prescindissem do Núcleo histórico; a necessidade de um forte apoio financeiro da iniciativa privada exigiu que a visitação fosse record, colaborando para fortalecer a oferta de obras históricas e consagradas. Ao mesmo tempo, a Fundação Bienal procurou investir também na arte contemporânea - especialmente a brasileira e a latino-americana - com uma montagem realizada a partir de contaminações e do diálogo entre curadores, obras e artistas. Com a aceleração do processo de globalização, a Bienal preocupou-se em abolir as fronteiras entre as delegações nacionais e entre os segmentos históricos e contemporâneos, apostando no diálogo entre diferentes temporalidades e espacialidades na montagem da sua última exposição do século XX.

\section{UMA FEIRA MODERNA PARA UM PÚBLICO DE MASSA}

A Bienal de São Paulo atravessou a segunda metade do século XX como uma produção cultural que foi adquirindo uma determinada forma bastante parecida com as grandes feiras. Além da exposição, esse formato engloba várias atividades que ocupam espacialmente o evento, como os diversos stands de serviços e publicidade, lojas, lanchonetes, etc. Essas atividades e serviços paralelos ocupam, sem dúvida, um espaço cada vez maior e mais importante para o evento, tanto do ponto de vista financeiro da mostra, quanto das atrações oferecidas ao público.

Desde o seu início, em 1951, a Bienal já oferecia esses serviços e atividades paralelos à exposição, como intérpretes, informações e turismo, telégrafo, café, restaurante, livraria e papelaria, que visavam proporcionar facilidades aos visitantes (Tribuna da Imprensa, 13/10/1953). Além desses, a Bienal trazia uma seção de vendas, por meio da qual os artistas comercializavam suas obras expostas. Por esse serviço, a Bienal estabelecia uma comissão de $10 \%$ sobre o líquido das aquisições.

Parece estranho, a partir da Bienal que se conhece hoje, pensarmos num stand de vendas das obras expostas. Atualmente $\mathrm{o}$ aspecto comercial presente na Bienal não está mais ligado diretamente às obras originais, mas se pulveriza por uma série de atividades e facilidades à disposição do público. A XXIV Bienal trouxe, como uma de suas características básicas, o grande número de stands que ofereciam inúmeros serviços e produtos aos milhares de visitantes da mostra. Logo à entrada o visitante percorria a Alameda de serviços, um corredor repleto de lojas que buscavam divulgar, especialmente, algumas publicações da mídia impressa ou os serviços oferecidos por instituições financeiras, principalmente aquelas patrocinadoras do evento.

A loja de souvenirs é sempre um dos stands mais concorridos em qualquer grande museu do mundo e na bienal isso não é diferente. Andreas Huyssen comenta que dentro das novas características do museu contemporâneo está o sucesso dessas lojas, muitas delas responsáveis por maiores receitas do que a bilheteria das instituições. Ele aponta ainda, dentro do que denominou museumania, a expansão de veneráveis artigos de museus e do marketing da mostra estampado nas camisetas e pôsteres em que a obra de arte original surge como um meio para vender seus múltiplos derivados, e a reprodutibilidade como uma estratégia para aureolar o original (Huyssen, 1997:236). Com 
a venda de cartazes, canecas, chaveiros e camisetas, a obra de arte parece ganhar uma nova vida, uma nova aura. Para Walter Benjamin, a reprodução técnica significou a atrofia da aura, mas ao mesmo tempo libertou a obra de arte do domínio da tradição (Benjamin, 1993:168-69). Ele já sabia que essa reprodução técnica significava maior autonomia para o original, aproximando o indivíduo da obra e fazendo as coisas ficarem mais próximas, mas não imaginou que nas lojas de souvenirs dos museus e das exposições no final do século XX as obras originais pudessem ter sua aura reforçada pela venda de suas reproduções em objetos do cotidiano. No caso da Bienal de São Paulo, nas suas primeiras edições, a Seção de Vendas era a encarregada de comercializar os originais. Em suas últimas edições, as obras expostas foram comercializadas na forma de souvenirs. Esse processo relaciona-se a todo modo de vida condicionado pela dimensão estética que penetra o cotidiano das pessoas e define um consumo cultural voltado para a busca de distinção (Featherstone, 1995:97).

Mas as principais atividades da Alameda de serviços diziam respeito aos projetos pedagógicos concentrados na monitoria digital e no núcleo de educação. A monitoria digital era feita por um CD com 70 minutos de duração dividido em 46 faixas que podiam ser escolhidas conforme a preferência do visitante que alugasse o equipamento. O nome dos artistas eram associados a uma faixa onde o visitante ficava conhecendo dados sobre sua vida e obra. Uma discreta sinalização no chão indicava se o artista estava incluído no CD. Essa monitoria digital, que há muitos anos não é novidade nos museus estrangeiros, faz parte também do contexto de espetacularização das grandes exposições de arte e reflete o importante papel que a tecnologia desempenha como atrativo para o grande público.

A XXIV edição da Bienal de São Paulo foi concebida sobre três 'es': Exibição, Educação e Edição, três bases que refletiam as linhas de atuação propostas pelo presidente Júlio Landmann: a ênfase no arranjo curatorial da mostra, a aposta no projeto educacional e o investimento na produção de quatro catálogos cuidadosamente pensados e produzidos. Essas eram também as bases para a captação de recursos com a iniciativa privada, que poderia patrocinar as salas especiais, os catálogos ou os projetos pedagógicos. Assim, a Diretoria de Educação recebeu o apoio de US\$1 milhão do banco HSBC, uma quantia que foi uma novidade até para os organizadores do evento. O resultado foi um megaprojeto de educação envolvendo um intenso programa de cursos e seminários que atingiu mais de mil profissionais do ensino público e quase 120 mil alu- nos da rede pública que tiveram ingressos gratuitos. Monitores volantes passeavam pela mostra com seus grupos, enquanto dezenas de monitores fixos encarregavamse de tirar as dúvidas do visitante independente. Grupos especiais com portadores de limitações físicas ou mentais eram atendidos pelo Projeto Diversidade, que oferecia roteiros especiais em duas horas de atividades pela mostra.

Para um público de massa, a bienal necessitou de projetos pedagógicos também de massa. Isso foi necessário para que o evento cumprisse os objetivos civilizatórios que estavam na base de sua constituição desde os primeiros momentos. Pelo menos desde a segunda edição, em 1953, a atividade educativa foi considerada essencial para que o público pouco habituado à arte moderna pudesse ir incorporando a nova linguagem especialmente vinda com o cubismo e o abstracionismo. Desde então, a atividade pedagógica vem fazendo parte da missão que a bienal sempre carregou consigo: levar ao longínquo país latino-americano um pouco da arte e da cultura produzidas nos grandes centros cosmopolitas da Europa e dos Estados Unidos. Isso faz parte, de uma certa maneira, do longo processo de enculturação descrito por Jesús Martín-Barbero (1997), no qual um trabalho hegemônico realizado por um saber dominante atua na transformação de uma cultura popular atrelada a modos tradicionais de saber e de transmissão deste saber. Nesse contexto, a Bienal de São Paulo não apenas possui projetos pedagógicos, como ela própria é um longo e bem-articulado projeto pedagógico com cinco décadas de existência.

\section{NOTAS}

E-mail da autora: ritacao@uol.com.br

1. A doação total foi de 13 obras, entre guaches, óleos, têmperas e um móbile, que foram divididos entre Rio de Janeiro e São Paulo (Arruda, 2000:291).

\section{REFERÊNCIAS BIBLIOGRÁFICAS}

ADORNO, T. "A indústria cultural”. In: COHN, G. (org.). Comunicação e indústria cultural. São Paulo, Cia. Ed. Nacional, 1972.

ALMEIDA, F.A. de. O franciscano Ciccilo. São Paulo, Pioneira, 1976.

AMARAL, A. Arte para quê? A preocupação social na arte brasileira (1930 1970). São Paulo, Nobel, 1987.

AMARANTE, L. As bienais de São Paulo, 1951 a 1987. São Paulo, Projeto, 1989.

ARRUDA, M.A. do N. Metrópole e cultura: São Paulo meio de século. Tese de Livre-Docência. São Paulo, Departamento de Sociologia, FFLCH-USP, 2000

BAKHTIN, M. A cultura popular na Idade Média e no Renascimento: o contexto de François Rabelais. São Paulo/Brasília, Hucitec/Ed. da Univ. de Brasília, 1993. 
. Charles Baudelaire um lírico no auge do capitalismo. São Paulo, Brasiliense, 1989 (Obras escolhidas, v.III).

BENJAMIN, W. Magia e técnica, arte e politica. São Paulo, Brasiliense, 1993 (Obras escolhidas).

BORELLI, S.H.S. Ação, suspense, emoção: literatura e cultura de massa no Brasil. São Paulo, Educ/Estação Liberdade, 1996. . As regras da arte. São Paulo, Companhia das Letras, 1996.

BOURDIEU, P. A economia das trocas simbólicas. São Paulo, Perspectiva, 1999.

BUENO, M.L. Artes plásticas no século XX: modernidade e globalização. Campinas, Unicamp, 1999.

CERTEAU, M. de. A cultura no plural. São Paulo, Papirus, 1995. . A invenção do cotidiano: arte de fazer. Petrópolis, Ed. Vozes, 1996.

CHIARELLI, T. "As funções do curador, o Museu de Arte Moderna de São Paulo e o Grupo de Estudos em curadoria do MAM". In: MUSEU DE ARTE MODERNA DE SÃO PAULO. Grupo de Estudos em curadoria. São Paulo, MAM, 1998.

COELHO, T. Guerras culturais. São Paulo, Iluminuras, 2000.

FEATHERSTONE, M. Cultura de consumo e pós-modernismo. São Paulo, Studio Nobel, 1995.

FERNANDES, F. A revolução burguesa no Brasil: ensaio de interpretação sociológica. Rio de Janeiro, Zahar Editores, 1975.

FERREIRA, E.C. "Refletindo e inovando a maneira de expor arte". In: FUNDAÇÃO BIENAL DE SÃO PAULO. XXIII Bienal Internacional de São Paulo Catálogo Universalis. São Paulo, FBSP, 1996, p.17.

FIORAVANTE, C. “A Bienal e o rigor”. Folha de S.Paulo, 22/11/1998.

FREIRE, M.C.M. Olhar passageiro - percepção e arte contemporânea na Bienal de São Paulo. Tese de Mestrado. São Paulo, Instituto de Psicologia - USP, 1990.

GRAMSCI, A. Literatura e vida nacional. São Paulo, Civilização Brasileira, 1986.

GONÇALVES, L.R. Sérgio Milliet, crítico de arte. São Paulo, Perspectiva/Edusp, 1992.

HUYSSEN, A. Memórias do Modernismo. Rio de Janeiro, UFRJ, 1997.

. Dos meios às mediações: comunicação, cultura, hegemonia. Rio de Janeiro, UFRJ, 1997

JORNAL HOJE. “A Bienal da Ibec”. São Paulo, 15/08/1951.

. "A Bienal - Manobra imperialista”. São Paulo, 02/09/1951.

. "Verdadeira farra de tubarões na inauguração da Bienal de Rockefeller". São Paulo, 21/10/1951.

JORNAL VOZ OPERÁRIA. "Bailam parceiros da Bienal". Rio de Janeiro, 13/10/ 1951.
MACHADO, L.G. "Introdução". In: MUSEU DE ARTE DE SÃO PAULO. I Bienal do Museu de Arte Moderna de São Paulo. São Paulo, MAM, 1951, p.14.

MARTÍN-BARBERO, J. Dos meios às mediações: comunicação, cultura e hegemonia. Rio de Janeiro, UFRJ, 1997.

MATTELART, A. Comunicação-mundo: história das idéias e das estratégias. Rio de Janeiro, Vozes, 1994

$$
\text { . A globalização da comunicação. Bauru, Edusc, } 2000 .
$$

MILlIET, S. Diário crítico. São Paulo, Martins/Edusp, v.VII a X, 1981.

MORAIS, F. Chatô, o rei do Brasil. São Paulo, Companhia das Letras, 1994.

MORIN, E. Cultura de massas no século XX: o espirito do tempo-1: neurose. Rio de Janeiro, Forense-Universitária, 1987.

OLIVEIRA, L.H.T.M. de. A bienal pop: a pop art analisada através das representações dos Estados Unidos e do Brasil na IX Bienal Internacional de São Paulo. Tese de Mestrado. Campinas, Instituto de Filosofia e Ciências Humanas, Unicamp, 1993

OLIVEIRA, R. de C.A. A Bienal de São Paulo: forma histórica e produção cultural. Tese de Doutorado. São Paulo, Programa de Ciências Sociais, PUC-SP, 2001.

ORTIZ, R. A moderna tradição brasileira: cultura brasileira e indústria cultural. São Paulo, Brasiliense, 1991.

PEDROSA, M. Dos murais de Portinari aos espaços de Brasília. São Paulo, Perspectiva, 1981

. Política das artes. São Paulo, Edusp, 1995.

PENTEADO, Y. Tudo em cor-de-rosa. Rio de Janeiro, Nova Fronteira, 1976

PONTES, H. Destinos mistos: os críticos do Grupo Clima em São Paulo (19401968). São Paulo, Companhia das Letras, 1998.

REVISTA ARTFORUM. Nova York, v.XXXVIII, december 2000.

SIMÕES FILHO, P. “A Bienal de São Paulo”. In: MUSEU DE ARTE MODERNA DE SÃO PAULO. I Bienal do Museu de Arte Moderna de São Paulo. São Paulo, MAM, 1951, p.10.

TRIBUNA DA IMPRENSA. "Em fase final os preparativos para a II Bienal de São Paulo". 13/10/1953.

VILLARES, L. “Apresentação". In: FUNDAÇÃO BIENAL DE SÃO PAULO. XVII Bienal de São Paulo. São Paulo, FBSP, 1983, p.3.

WILLIAMS, R. Cultura e sociedade (1780-1950). São Paulo, Cia. Ed. Nacional, 1969.

Marxismo e literatura. Rio de Janeiro, Zahar Editores, 1979.

Cultura. São Paulo, Paz e Terra, 1992

. La política del modernismo: contra los nuevos conformistas. Buenos Aires, Ediciones Manantial, 1997. 